\title{
Position-related subject properties change in English
}

\author{
Erwin R. Komen \\ Radboud University Nijmegen and SIL-International \\ E-mail: E.Komen@Let.ru.nl
}

\begin{abstract}
Subjects in Old English can occur in a number of different positions. Their distribution changes over time, especially during and after the loss of the non-obligatory verbsecond word order that characterised Old English. A question that has not been raised is whether the disappearance of subject positions is preceded by a loss of subjectspecific properties connected with these positions. This paper investigates two such properties: subject-deletion under coordination, and subject-position related verb type selection. The decrease of the Middle Field and Post Field subject positions is, indeed, preceded by a steeper decline in the former property, while the latter property reveals an increasing specificity in terms of the types of verbs associating with the Post Field position.
\end{abstract}

\section{Introduction}

Subjects in English, including in the older stages of the language, have been prominent in many studies; Hulk and van Kemenade (1993) have looked at (nominative) case assignment as well as agreement, Rissanen (1999) has investigated word order patterns involving postverbal subjects and negation, Los and Dreschler (2012) have regarded the subject's increasing role as local anchor, to name but a few examples. The relation between subjects and information structure too has been explored extensively_both diachronically as well as synchronically: van Kemenade (1987) and others have pointed out that pronominal subjects in Old English (OE) tend to occur immediately before the finite verb, whereas nominal ones follow the finite verb; Hinterhölzl and van Kemenade (2012) as well as van Kemenade and Westergaard (2012) suggest that, at least for Middle English (ME), the crucial factor is givenness: the finite verb serves as a boundary between given and new material in the clause; Prince (1992) has reviewed the correlation between information status and definiteness for subjects in Present-day English (PDE); Lambrecht (2010) has focused on "new" subjects in PDE; Biberauer and van Kemenade (2011) have regarded mapping between the positions and the informational content of subjects in OE, and Dreschler (this volume) investigates the information status of late subjects in $\mathrm{OE}$. 
As for the versatility of the subject's position, the PDE examples (1a-c) and the historical English examples (1d-f) illustrate some of the different positions within the clause where subjects occur and have occurred (and some of these positions will turn out to be too ambiguous in terms of a syntactic analysis, as Warner (2007) describes).

(1) a. Other food colourings, particularly the synthetic ones, have been known to cause allergic dermatitis, mainly in food workers exposed to large amounts.

[BNC BMI:617]

b. Who did you rob for this?

[BNC HTY:160]

c. Until the end of the war so very few folk had beards, and then only short ones nicely trimmed, but into the room came a most handsome young man with a black fuzz of over eight inches.

[BNC-UK B2E:1213]

d. But from that time he heard no more from him. [reeve-1777:18]

e. Nor should a Horse be rejected on account of a large belly.

[skeavington-184x:69]

f. Fæder her is cumen an eunuchusof cinges hirede. [coeuphr:142]

father here has come a eunuch of the.king's household

'Father, a eunuch from the king's household has arrived.'

g. (An Antiochia pare ceastre wæs sum cyningc Antiochus gehaten:)

æfterpæs cyninges naman wæs seo ceaster

after that king's name was this city

Antiochia geciged. [coapollo:3-4]
[

Antioch called

'(In the city of Antioch there was a king named Antiochus,)

from whom the city itself took the name Antioch.'

The subject positions differ over the various stages of the English language; in terms of surface structure as well as in their syntactic interpretation. Since English started out as a verb-second language, it makes sense to take the position of the finite and non-finite verbs as landmarks, akin to the Germanic topological 
field model (Behaghel, 1909, Speyer, 2010). This model distinguishes subjects in the Fore Field (1a,d), the Middle Field (1b,e), and the Post Field (1c,f,g), as illustrated in Table 1 (taken from coeuphr:25).

Table 1 An illustration of the topological field model applied to Old English

\begin{tabular}{|c|c|c|c|c|}
\hline $\begin{array}{l}\text { Fore } \\
\text { Field }\end{array}$ & $\begin{array}{l}\text { Left } \\
\text { Bracket }\end{array}$ & Middle Field & $\begin{array}{l}\text { Right } \\
\text { Bracket }\end{array}$ & Post Field \\
\hline $\begin{array}{l}\mathrm{Pa} \\
\text { then }\end{array}$ & $\begin{array}{l}\text { wurdon } \\
\text { were }\end{array}$ & $\begin{array}{l}\text { hire yldran swiđlice } \\
\text { her parents exceedingly }\end{array}$ & $\begin{array}{l}\text { geblissode } \\
\text { made-joyful }\end{array}$ & $\begin{array}{l}\text { purh hi } \\
\text { through her }\end{array}$ \\
\hline
\end{tabular}

The Fore Field subjects are syntactically interpreted to be in the CP (especially when they are clause-initial) or in a functional projection that is sometimes labelled AgrSP, residing between the CP and the TP. Middle Field subjects are interpreted as being in the specifier of the TP, and Post Field subjects are argued to have been left behind in the VP; Warner (2007) labels these, especially when they are clause-final, as "late subjects". ${ }^{1}$

The positional distribution of subjects changes in the history of the English language. The Fore Field was one of the options in OE, as Komen (2013: 246) shows, but in PDE it hosts the vast majority of subjects. ${ }^{2}$ The Middle Field subject position was used relatively often in OE, as in (1g), but PDE reserves it for subjects within a few clearly identifiable contexts, such as negation (1e) and questions (1b). These latter two illustrate the 'obligatory' verb-second environments that have remained in the language from OE onwards. ${ }^{3}$ The

\footnotetext{
${ }^{1}$ One analysis for the late-subject-construction is that the subject is extraposed (rightward movement) here. The fact that the verb in this construction is almost invariably an unaccusative supports an additional analysis in which the subject is situated in its original position, since subjects of unaccusatives start as objects of the verb (see Warner (2007), following Burzio's (1986) unaccusative generalization).

${ }^{2}$ The percentages provided in footnote 8 of Komen (2013) show OE as having $62 \%$ of the subjects in the Fore Field, 4\% definitely in the Middle Field, 3\% in the Post Field, and 31\% as ambiguously in the Middle Field or the Post Field. The table shows PDE as having over $98 \%$ of the subjects in the Fore Field.

${ }^{3}$ Instead of having the subject appear in different locations, mainstream analyses of English syntax have the subject in one location (the specifier of TP), while the verb moves around. Accounts of $\mathrm{OE}$ and ME have multiple subject and verb positions. I nevertheless use the topological model consistently in this paper, because it is a fitting starting point for OE as a verbsecond language, and keeping the model throughout time allows one to see where the changes in English occur from a fresh perspective.
} 
subject in (1g) results from a non-obligatory verb-second environment, where the first constituent provides a neutral link to the immediately preceding context. This and other non-obligatory verb-second occurrences have completely disappeared from English (Los et al., 2012). Post Field subjects were among the options in OE (1f) but have become entrenched to particular presentational situations in PDE (1c). What I have sketched here is the broad picture. In section 5.1, I will present a quantificational account of the historical change in these positions.

A question that has not been raised, as far as I have been able to establish, is if there is a correlation between the different subject positions and the properties that subjects can have in these positions, and this paper aims to start off research in that area. ${ }^{4}$ Work into subject properties as such has focused on the validity of calling noun phrases (NPs) with particular characteristics "subject" or not, for example whether non-nominative case experiencers in English can be called “subjects" (Allen, 1995, Coniglio, 2013). Research into subject properties has rendered support to the arguments for or against calling non-nominative case NPs subjects. I will, however, only take into account nominative-case subjects, which means that the research done into subject properties so far is only partly usable for the questions I raise. The subject position within the clause, for instance, is a property when it comes to the question whether dative-case NPs can be called subjects, but the subject position is a dependent variable for my purposes.

In this paper, I investigate the order of events surrounding the attrition of subject positions other than the immediately preverbal one. While none of the subject positions have vanished completely, some, as will become clear, have decreased dramatically in their use. I will first of all consider the order of events surrounding the decrease of the Middle Field and Post Field subject positions. My main hypothesis here will be that the loss of subject properties for subjects occurring in these positions precedes the loss of the positions themselves. I expect the percentage of subjects showing subject properties in these positions to decrease faster than the percentage of subjects occurring in these positions. The implication of these expectations would be that subject-property loss in a particular syntactic position is a forewarning of the loss of such a position for subjects.

Having considered the attrition of the Middle Field and Post Field subject positions, I next zoom in on the subject properties associated with different positions within the Fore Field: the clause-initial position versus the

\footnotetext{
${ }^{4}$ It has not been raised in the field of historical English linguistics as such. Credit for asking this question is due to Professor Robert Van Valin, who brought it up at my Ph.D. defense in June 2013. His question has been the inspiration for the research described here.
} 
immediately-preverbal position. The reason for this is that the English language has changed considerably in terms of Fore Field make-up and usage, and although this paper will not go into a detailed analysis of all the aspects of the Fore Field, a closer look at the subject positions within the Fore Field is in line with the research question addressed here.

\section{Subject positions}

In this section, I would like to define the different subject positions for the main clause in a more detailed way, and number them from " 1 " to " 5 ". The subject positions should, ideally, be defined in terms of their syntactic structure. This is, however, problematic, given the differences in opinion as to what the structure looked like, how it changed and where exactly the subject positions should be interpreted. I will, therefore, take an approach where I investigate the properties of subjects in positions that are defined in terms of particular landmarks, and I will make the connection with the possible underlying structure where possible. I use the landmarks that have been mentioned briefly in section 1 (compare also Table 1):

\section{(2) Landmarks used to determine the subject position}
a. Start of the clause
b. End of the clause
c. The finite verb
d. The first non-finite verb, or an alternative indicator

The start (2a) and the end (2b) of the clause are clear points, and when the finite (2c) and non-finite (2d) verb (if existing) are taken as landmarks, main clauses divide into three areas: the Fore Field, which is the area between the start of the clause and the finite verb, the Middle Field, which is the area between the finite and the non-finite verb, and the Post Field, which is the area after the non-finite verb until the end of the clause. This matches the topological field model used for German (see section 1). Taking the three clause areas of the topological field model into account, I define five possible positions for the subject, as indicated in (3). ${ }^{5}$

\footnotetext{
${ }^{5}$ Note that the five possible subject positions do not cover all possibilities. Excluded from the current research are two positions: Fore Field spanning subjects (which could be labelled as "12") and Post Field spanning subjects (these could be labelled as “4-5"). The syntactic
} 
$\left[S b j_{1}-\mathrm{XP}-S b j_{2}-\mathbf{V}_{\mathbf{f}}-\ldots S b j_{3} \ldots-\mathbf{V}_{\mathbf{n}}-S b j_{4}-\mathrm{X}-S b j_{5}\right]$

[---Fore Field---] [---Middle Field---] [---Post Field---]

\section{(3) Subject positions}

“1” - Immediately clause-initial (and followed by a non-verb)

“2” - Immediately preverbal (but not clause-initial)

“3” - Middle field

“4” - Immediately postverbal (but not clause-final)

“5”- Clause final

Subjects are recognized as being in position "1" when they are clause-initial (skipping a possible conjunction) and when they are followed by at least one other constituent before the finite verb (or auxiliary) follows (4a). Clauses do not need to have a non-finite verb for a subject to be identified as a position " 1 " one. The resulting kinds of subjects are likely to be CP specifiers in syntactic terms.

Position "2" subjects, such as (4b), occur immediately before the finite verb (or auxiliary), but they are not clause-initial; they must be preceded by at least one other constituent (and conjunctions do not count). The position "2" subjects syntactically most probably reside in the specifier of the projection headed by the finite verb (or the auxiliary): the TP, or a "Functional Projection" (FP) that is used by pronominal subjects in OE (van Kemenade, 1999). ${ }^{6}$

Position " 3 " subjects, such as (4c), are only counted as such if the hosting clause has both a finite verb (or auxiliary) and a non-finite verb (such as a past or present participial); they reside anywhere between these two verbal landmarks. Syntactically they are either in the specifier of the TP (e.g. for many lexical subjects in OE), or they are stuck in the VP (e.g. when the TP is headed by do or an auxiliary in PDE).

interpretation of these subjects is not straight forward, which is why I have excluded them from this initial research; they deserve separate attention.

${ }^{6}$ The generic term "Functional Projection" has been introduced to avoid prejudging its precise status. Warner (2007) labels it as an AgrSP. 
(4) a. And hi đa eft sendon ærendracan to Rome. [cobede:383] and they then again sent messengers to Rome

"Hereupon messengers are again sent to Rome."

b. Betweoh đas đing ba se halga wer Agustinus

between that thing then the holy man Augustine

ferdeofer sæ. [cobede:588]

sailed across sea

"In the meantime, Augustine, the man of God, set out across sea."

c. Paweard hegehyrt purh pas word. [coeuphr:236]

then was he heard through that word

"He was answered by this message.”

The interpretation of position "4" and "5" subjects requires a finer-grained look at potential situations:

(5) Post Field subject positions

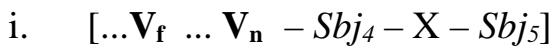

ii. $\quad\left[\begin{array}{lll}\ldots \mathbf{V}_{\mathbf{f}} & \ldots & \left.\mathbf{P r t}-S b j_{4}-\mathrm{X}-S b j_{5}\right]\end{array}\right.$

iii. $\quad\left[\ldots \mathbf{V}_{\mathbf{f}} \ldots \mathbf{D O}-\mathrm{Sbj}_{4}-\mathrm{X}-\mathrm{Sbj}_{5}\right]$

Position " 4 " and position " 5 " subjects occur in the Post Field, and this field can be recognized in a number of different ways: (i) it is the area after the non-finite verb in clauses that have a finite verb and a non-finite verb, (ii) it is the area after the verb-particle in clauses that consist of a finite verb and a particle, and in clauses that only have one (finite) verb, it is (iii) the area following the postverbal direct object (if the verb is transitive). ${ }^{7}$

\footnotetext{
${ }^{7}$ Situation (ii) reflects the standard assumption that verb complements (such as directional adverbs with verbs of motion), similar to non-finite lexical verbs, do not move; they mark the VP. Situation (iii) involves subjects occurring after the direct object, which could be interpreted as movement of the direct object out of the VP, while the subject lags behind. Subjects that fill the whole area following the verb, as in example (1c), are not assigned to either " 4 " or " 5 "; they are not part of this study.
} 
(6) a. On pæmgeare asprong up $\#$ Epna fyr onSicilium

$$
\begin{aligned}
& \text { in that year sprang up Etna fire on } \begin{array}{c}
\text { Sicily } \\
\text { [cobede:588] }
\end{array} \\
& \text { [colen }
\end{aligned}
$$

"In that year, the volcano Etna erupted on Sicily."

b. pa wæs gongende in to him sum parabrođra [cobede:1880]

then were going in to him some of.their of.brother

"Then, some of the brothers were visiting him."

Position " 4 " subjects, then, occur in the Post Field, but are not clause-final, as in (6a), while position "5" subjects occur in the Post Field and are always clausefinal, as in (6b). From a syntactic point of view, position "4" and "5" subjects can be regarded as 'left behind' in the VP (or alternatively as resulting from rightward movement, extraposition). A more detailed account of the syntactic interpretation of uninverted, inverted and late subjects can be found in Warner (2007).

\section{Subject properties}

I defined "subject properties" in this study as those syntactic characteristics that are associated with NPs that occur in a position where the majority of subjects occur. $^{8}$ Typical subjects in English, then, have the following properties (Keenan, 1975):

${ }^{8}$ This means that I do not take the position within the clause to be a subject property. Doing so would give a circular reasoning in the questions that I seek to answer in this paper. In other contexts, however, it may be quite useful to take the syntactic position of a constituent as a subject-indicating property. 


\section{(7) Properties associated with typical subjects in English}

a. Agreement with the finite verb in number and person

b. Nominative case marking

c. Triggering deletion under coordination

d. Omission of the subject of an infinitive under control by the main clause

e. The subject has a special relation with the verb: it is the external argument of it

It is not the case that all of these properties are unique just for subjects in English, nor is it the case that all of these properties can be seen at work in all subjects in all stages of the language. As for the uniqueness: nominative case is the usual case for subjects, but nominative case as such is not a clear indicator of subjecthood (nominal complements in copula clauses have nominative case took, for instance). Case itself has all but left the English language (there still is a remnant in the pronominal system, though), and some OE subjects have nonnominative case (external arguments of experiencer verbs occur in the dative).

Cole et al. (1980) convincingly showed that a distinction should be made between at least two kinds of subject properties: coding properties and behavioural properties. ${ }^{9}$ The former are represented by $(7 a, b)$ in the list, while the latter are expressed in $(7 \mathrm{c}, \mathrm{d})$. The property in (7e) does not seem to fit any of these categories, it is more fundamental. In this paper, I will only look at two of the properties listed in (7). I will not be taking the coding properties (7a,b) into account in this study, since I do not expect there to be subjects that do not trigger agreement with the finite verb (7a), and since the subjects that will be looked at are going to be nominative case by design (7b). ${ }^{10} \mathrm{I}$ leave out of this discussion subject control (7d) for several reasons: this property is inherent for any subject (so no changes are to be expected), it is not straightforward to determine control situations in the parsed corpora, and their numbers are likely to be too few to make conclusions. This leaves two properties that are evaluated

\footnotetext{
${ }^{9}$ Coding properties are 'coded' in the morphosyntax (e.g. nominative case, control of verb agreement), while behavioural properties are not.

${ }^{10}$ This is not to say that (7a,b) are no clear indicators of subjecthood: they are. They are no help, however, in the task of this study: determining which characteristics make a subject appear in a particular position.
} 
in the current research: deletion under coordination (7c) and the the subject-verb relation (7e).

\section{Method}

The research question, in sum, is: which subject properties associate with which positions and how does that change in time? This paper answers that question by finding main-clause subjects in historical texts and reviewing those subjects that appear in the five positions defined in section 2. All of these subjects are scrutinized for the type of verb they occur with (7e), and whether or not they cooccur with deletion under coordination (7c). The texts consist of those that are found in four historical English corpora (Kroch et al., 2004, Kroch et al., 2010, Kroch and Taylor, 2000, Taylor et al., 2003). The texts in these corpora range from Old English (OE; starting roughly at 900 A.D.) to late Modern English (LmodE; ending at 1914).

The texts come in a treebank format: they have been syntactically annotated by the corpus designers. For the research described in this paper, I make use of the $\mathrm{xml}$ variants of the texts, which were created with the "Cesax" program. ${ }^{11}$ These $x m l$ coded texts are queried through the CorpusStudio program by using queries written in the Xquery language (Boag et al., 2010). ${ }^{12}$

The queries that I have written find main-clause subjects, determine the position of these subjects with respect to the landmarks defined in section 2, and assign them a subject position number ranging from "1" (clause-initial Pre Field) to "5" (clause-final Post Field). Many of the subjects will be in a position where they cannot receive a unique subject position number as defined in (3). These subjects reside either somewhere in the Fore Field, but are not clause-initial and do not immediately precede the finite verb, or they are somewhere in the Post Field, but they are not clause-final and do not immediately follow the non-finite verb. They are excluded from the experiments in this paper, since the translation of their surface position to their syntactic position is too ambiguous.

One set of queries checks to see if a particular subject displays one or both of the subject properties we are interested in: deletion under coordination and verbtype selection. The queries check for the first property, subject deletion under coordination, by (a) looking for a subsequent clause (which may occur as an "IPMAT" under a sibling "CONJP" or as an "IP-MAT" in the following line), (b) checking if this clause has an empty subject (subjects that are deleted under conjunction are coded in the treebank texts as $\left.{ }^{*} \operatorname{con}^{*}\right)$.

\footnotetext{
${ }^{11}$ Cesax: http://erwinkomen.ruhosting.nl/software/Cesax.

${ }^{12}$ CorpusStudio: http://erwinkomen.ruhosting.nl/software/CorpusStudio.
} 
The second property evaluated in this paper, verb-type selection (or 'subjectverb relation') as in (7e), is evaluated by noting the type of the lexical verb used in the clause. I distinguish four situations: (i) the lexical verb is the copula, (ii) it is an intransitive verb, (iii), it is a transitive one, (iv) the voice is passive. The queries that take care of this evaluation take into account the kind of finite verb, the presence or absence of an object NP, and the presence or absence of a nonfinite verb form. It will become clear in the course of this study that it is important to look at the changes in the distribution of subject-verb relation types that appear in the different subject positions. The distribution of these subjectverb relation types as such, however, is not a subject property that can be 'lost' in the course of time. What can change in terms of subject distribution is the "diversity" of subjects appearing in a particular position. I hypothesize that positions with subjects that are diverse in terms of verb-type selection are not likely to disappear. I hesitate to offer a hypothesis for subject positions that become more specific in terms of verb-type selection over time. Specificity (the reverse of diversity) is a sign of entrenchment or fossilisation. Fossilised constructions can either remain in the language (as are the verb-second situations in present-day English, which have become part of syntax: the verb-second word order is required for constituents of particular syntactic categories), or they can disappear, provided there is a good alternative for them. ${ }^{13}$

\section{The change in subject properties per subject position}

This section presents the results of the queries described in the previous section. First of all, the changing occurrence of subjects in particular positions is discussed, and then the change in subject properties related to these positions.

\subsection{Changing subject positions}

The hypothesized decline of subject properties associated with subjects appearing in different positions in the English main clauses should be compared with the decline of these positions for subjects as such. Results of the query that illustrate the decline of main-clause subject positions are shown in Figure 1 (the "Fore Field" includes positions 1+2, the "Middle Field" position 3, and the "Post Field" positions $4+5){ }^{14}$

\footnotetext{
${ }^{13}$ I use the term 'construction' in a form-oriented sense: a particular constellation (word order) of constituents characterized by their syntactic categories. The syntactic category of a nominal question constituent would, for instance, be NPwH (e.g. 'what' or 'which person').

${ }^{14}$ The symbols at the horizontal axis indicate divisions of the time periods: O1-4 are part of OE (O1-2: 450-950, O3-4: 950-1150), M1-4 belong to ME (M1: 1150-1250, M2: 1250-1350, M3: 1350-1420, M4: 1420-1500), E1-3 represent eModE (E1: 1500-1569, E2: 1570-1639, E3: 16401710) and B1-3 are the divisions of LmodE (B1: 1700-1769, B2: 1770-1839, B3: 1840-1914). The query only regards overtly expressed subjects, which may, for the rest, be of any type. Only
} 


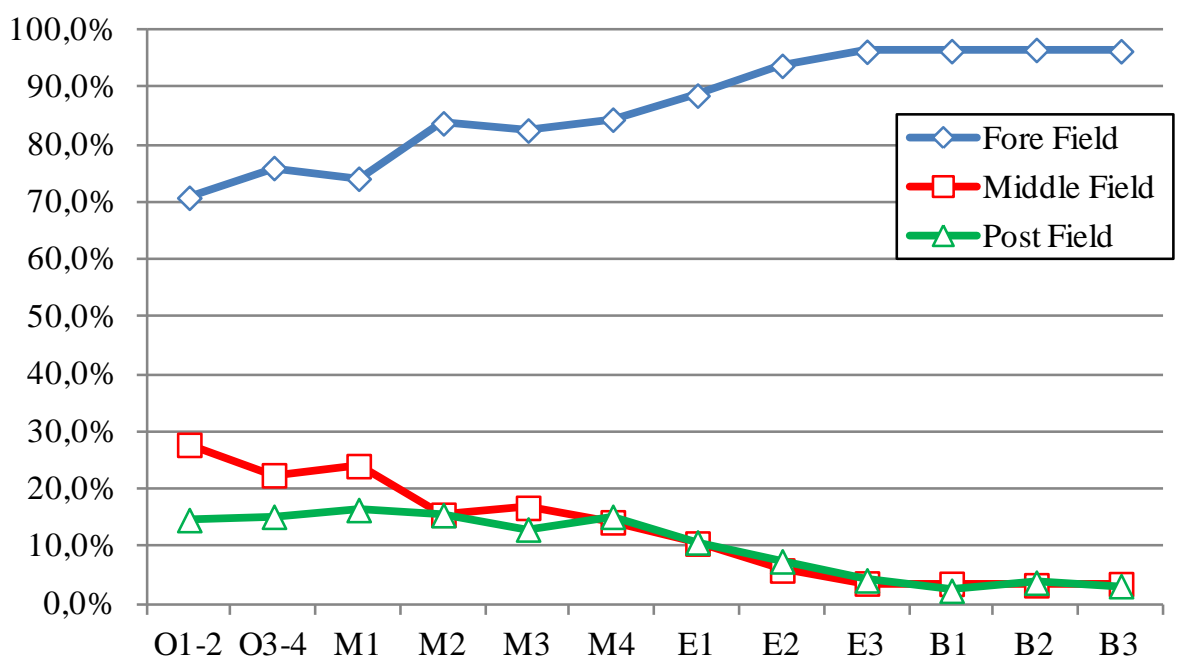

Figure 1 The division of subjects over different positions

Subjects in OE start out with a preference for an appearance in the Fore Field, and this preference increases into LmodE: the Fore Field gradually replaces the alternatives. The Middle Field subjects start out with an $28 \%$ contribution in OE, waver between 25\% and 15\% during Middle English (ME), but end up with less than 5\% in LmodE. Subjects occurring in the Post Field have a contribution of about 15\% in the first half of OE, and this situation continues until eModE. Their contribution subsequently decreases to about 5\% in LmodE.

When we, instead of looking at the division in fields, distinguish the five positions that are defined in (3), then a slightly more pronounced picture results: ${ }^{15}$

\footnotetext{
main clauses are taken into consideration. The corpus research project that has been used to query the data for this research is available at http://erwinkomen.ruhosting.nl.

${ }^{15}$ This finer-grained picture only contains subjects that are unambiguously in one of the five positions, which means that subjects whose position cannot be determined exactly (Fore Field and Post Field subjects that do not have a clear right or left border) are not taken into account.
} 


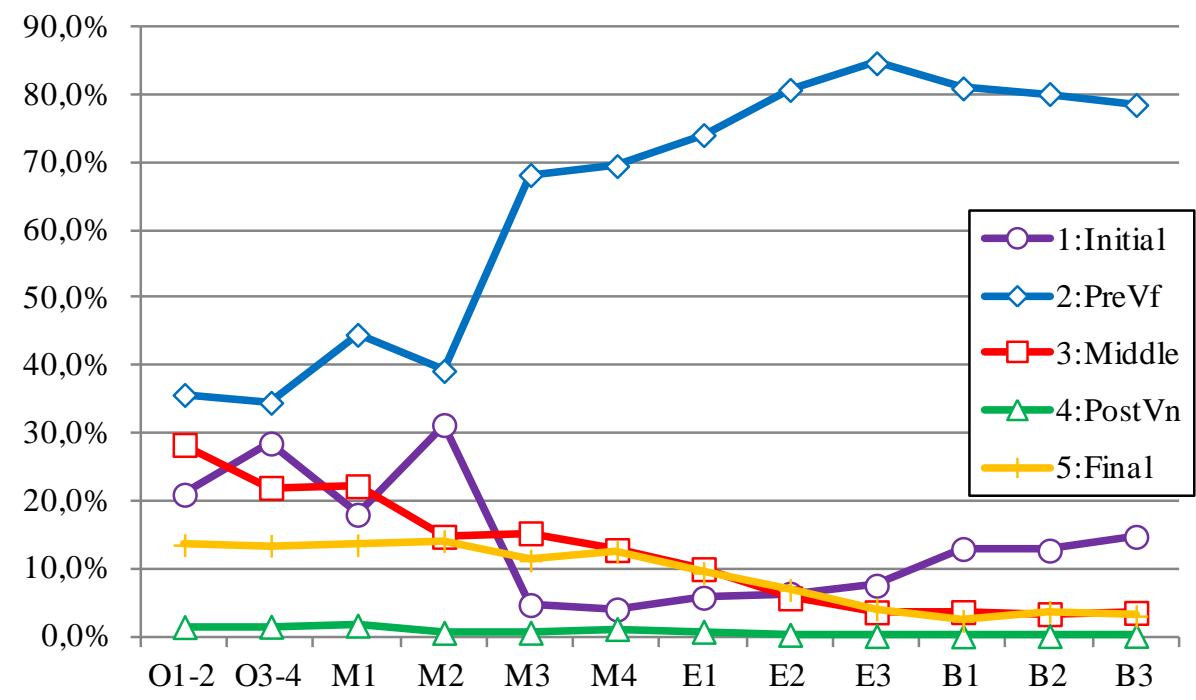

Figure 2 The division of subjects over the five positions defined in (3)

The global trends in this picture nicely illustrate the loss of verb-second: the $\mathrm{OE}$ and early ME periods see a large diversity in subject-position distribution, but when the non-syntactic part of verb-second has by-and-large disappeared in late $\mathrm{ME}$, the preference for PreVf subjects prevails.

The Fore Field divides into clause-initial "1" and pre-finite verb "2". Figure 2 suggests that the immediately clause-initial position " 1 " comes into disfavour halfway in ME, after which it gradually gains prominence again. This is, however, not completely fair, since what Figure 2 shows is a relative division. What is clear, is that the winner of the subject positions is the immediately preverbal position " 2 ".

As far as the Post Field is concerned, the picture reveals that the steady decline in the Post Field from 15\% in OE to 3\% in LmodE is predominantly caused by a decline in the clause-final position " 5 " subjects; the position " 4 " subjects, those that are not clause-final, but immediately follow the non-finite verb (or another complement), are used very infrequently throughout.

In sum, position "1" (initial) goes up and down, position "2" (pre-verbal) steadily increases, position " 3 " and " 5 " steadily decrease, and position " 4 " had and has a negligible contribution.

\subsection{Subject elision under coordination}

What we will do in this section is first have a look at the broad picture, and then zoom in on the detailed pictures of the individual subject positions. 


\subsubsection{The global picture}

Figure 3 shows the global trend of subject elision under coordination occurring as indicator of the degree of 'subjectness' of the three fields; the figure only counts subjects that have subject elision in the subsequent clause.

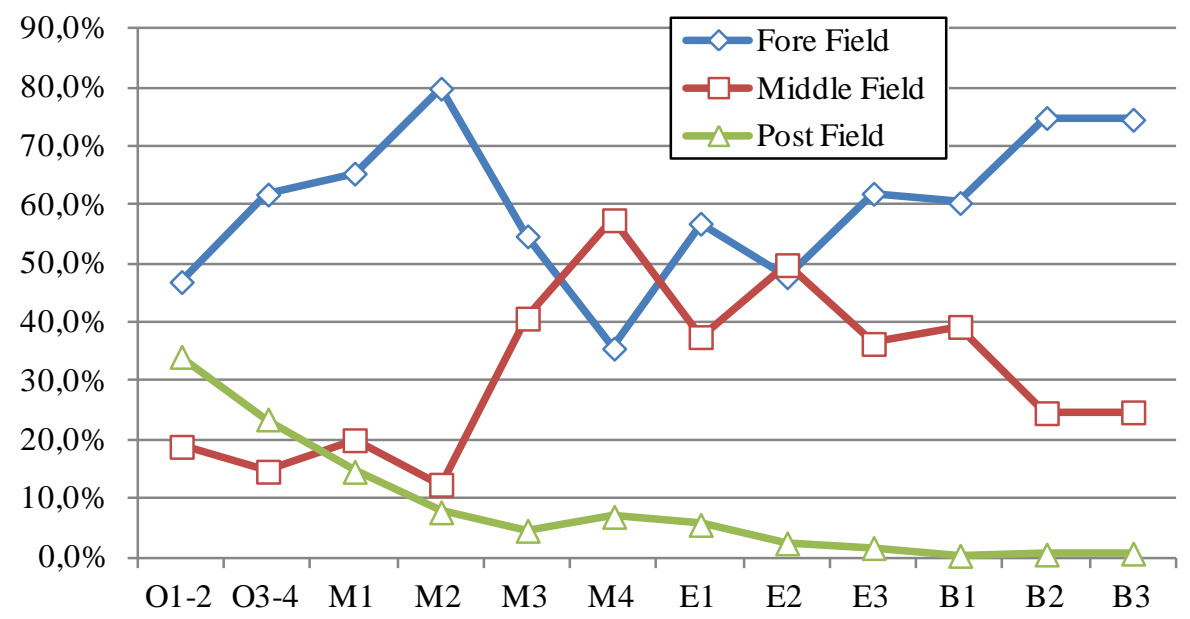

Figure 3 Subject elision under coordination in the three Fields

What we see here is the relative subjectness associated with the Fore Field, Middle Field and Post Field. The subjectness of the Post Field decreases steadily from OE to LmodE. The Middle Field is less of a subject-host in OE, but from the second part of ME starts to compete with the Fore Field, the timing of which coincides with the loss of the non-obligatory verb-second. It is only towards the end of eModE that the Fore Field appears as the winner in terms of subjectness.

The trend lines in Figure 3 cannot really be compared with the global picture that displays the changing subject position in Figure 1, because they represent different measures: Figure 1 shows the proportion of subjects occurring in one of the three Field areas, whereas Figure 3 shows the proportion of subject elision under coordination in the three areas. In order to answer the research question raised in this paper, it is necessary to have a more detailed look at the elision behaviour as measured in each of the subject positions. We will first look at the disappearing subject positions " 3 ".- 5 " in the Middle Field and the Post Field, and only then consider the remaining ones "1" and "2" in the Fore Field.

\subsubsection{The Middle Field position " 3 ”}

We can see how the amount of subject elision under coordination changes at position “ 3 ”, the Middle Field position, by dividing the number of subject elision 
tokens at that position by the overall number of subjects occurring at position " 3 ". This trend needs to be compared with the percentage of Middle Field subjects, as shown in Figure 4. ${ }^{16}$

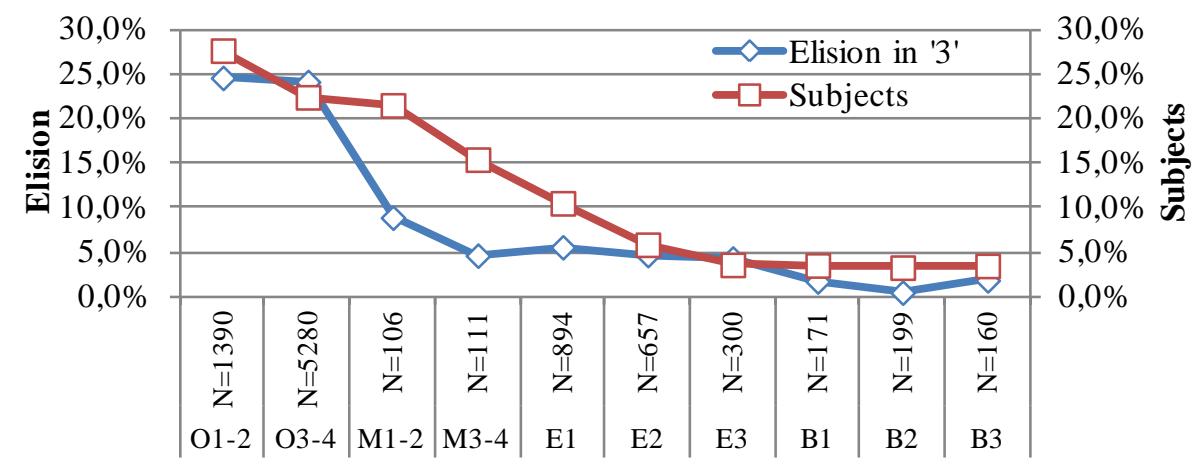

Figure 4 Relative subject elision at position "3"

OE starts out with about $25 \%$ of the Middle Field subjects showing the elision under coordination property, such as (8a), where the subject is bolded and the finite and non-finite verbs are underscored. This percentage rapidly falls to $5 \%$, however, in ME. An even further drop in percentage to about $2 \%$ occurs in LmodE.

(8) a. Dahira brydgumagehyrde pæt heo losad wæs,

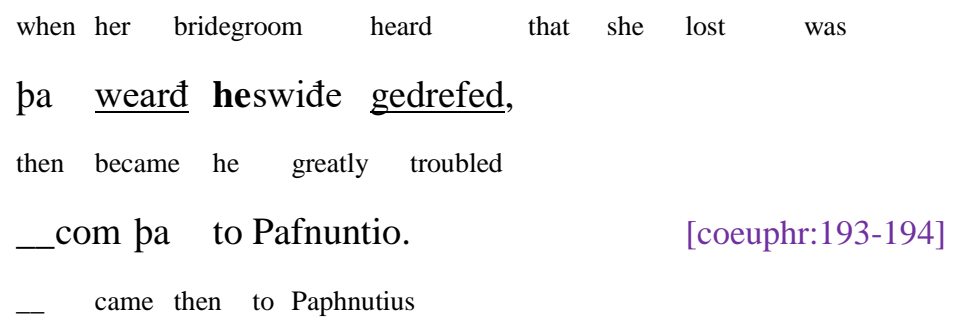

"When her bridegroom heard that she was lost, he became greatly troubled and _ came to Paphnutius.”

\footnotetext{
${ }^{16}$ As for the elision line, only two of the transitions (O3-4 > M1-2, M1-2 > M3-4) are significant according to the two-tailed Fisher's exact test $(\mathrm{p}<0,01)$. The transitions from $\mathrm{OE}>\mathrm{ME}$ as a whole, and from eModE $>$ LmodE are significant $(p<0,01)$.
} 
b. When it shall please the Almighty Ruler to unfold the signs to us; then shall he that is of a willing mind to receive the doctrine, be shewn its meaning, and will profit from it himself.

[wollaston-1793:111-112]

There are only three LmodE occurrences, and they are all from Bible translations, which are known to retain older language forms. The latest example, which occurs in 1793 (the B2 period), is in (8b).

The elision drop occurring between $\mathrm{OE}$ and $\mathrm{ME}$, however, precedes the attrition of the Middle Field as a whole: the percentage of subjects occurring in the Middle Field diminishes only slightly from the end of OE until the beginning of eModE. The picture from the Middle Field position "3", then, confirms the hypothesis stated in the introduction, that the loss of subject properties for a particular position precedes the loss of the position itself.

\subsubsection{The Post Field position "4"}

Position " 4 " is the one immediately following the non-finite verb; it is the initial position in those sentences with a Post Field, that have at least one constituent still following the subject. ${ }^{17}$

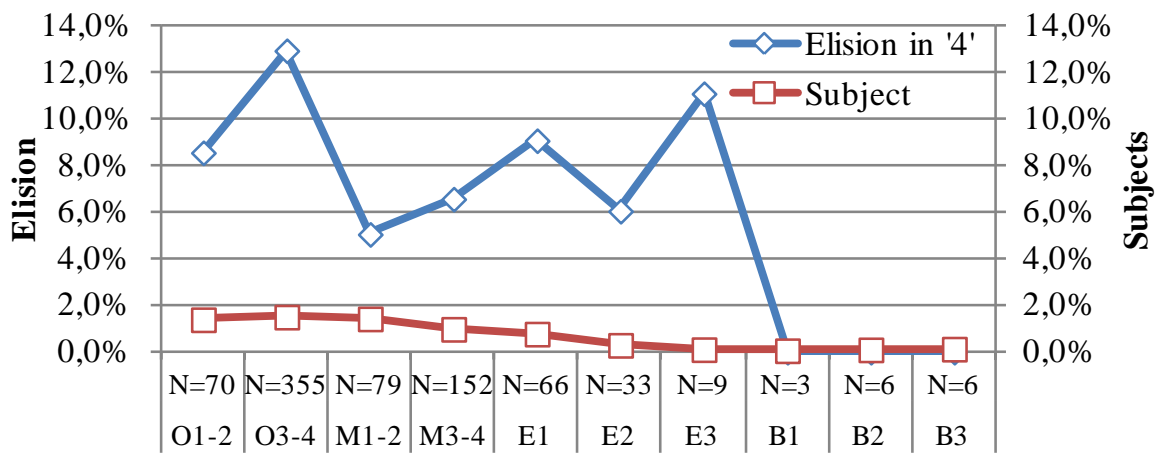

Figure 5 Relative subject elision at position “4”

What position "4" in the Post Field shows is in line with what we saw for position "3" in the Middle Field: the decline in subject-elision precedes the decline of the subjects occurring in this position. Numbers from eModE onwards are low, so

\footnotetext{
${ }^{17}$ None of the transitions in the "Elision” line are significant according to the two-tailed Fisher's exact test $(p<0,01)$. The transition from $O E$ as a whole to $M E$ is significant $(p<0,05)$.
} 
the picture is a bit distorted, but it is clear that subject elision ceases to occur in the Middle Field from lModE onwards.

(9) a. Đa wæs gestrangod Agustinus mid trymnysse

then was confirmed Augustine with confirmation

pæs eadigan fæder Gregoriusmid đam Cristes beowum,

of.the blessed father Gregory with the Christ's servants

đa pe mid him wæron;

those who with him were

\& _ hwearf eft onpæt weorc Godes wordto læranne

\& _ moved anew on the work of.God word to teach

\& _ com onBreotone. [cobede:525-527]

\& _ came into Britain

"Augustine, thus strengthened by the confirmation of the blessed Father

Gregory, returned to the work of the word of God, with the servants of

Christ, and arrived in Britain."

b. The meanewhyle com in kyng Arthure with an egir countenans, and _ founde Ulphuns and Brastias on foote, in grete perell of dethe, that were fowle defoyled undir the horse feete.

[cmmalory:681-682]

c. And by and by comes in Matt Wrenn from the Parliament-house, and tells us that he and all his party of the House, which is the Court-

party, are fools. [pepys-e3-p1:125-6]

The subject "Agustinus" in the OE text in (9a) is elided in the next two main clauses, and the same kind of elision is observed for the subject "king Arthur" in the ME example (9b) and for the subject "Matt Wrenn" in the eModE example in (9c).

\subsubsection{The Post Field position "5"}

Position " 5 " is the clause-final position, and it is part of the Post Field. This position occurs when the Post Field consists of more than one constituent: one 
or more constituents follow the non-finite verb (or if there is no Middle Field, they follow the finite verb), and the subject comes last. ${ }^{18}$

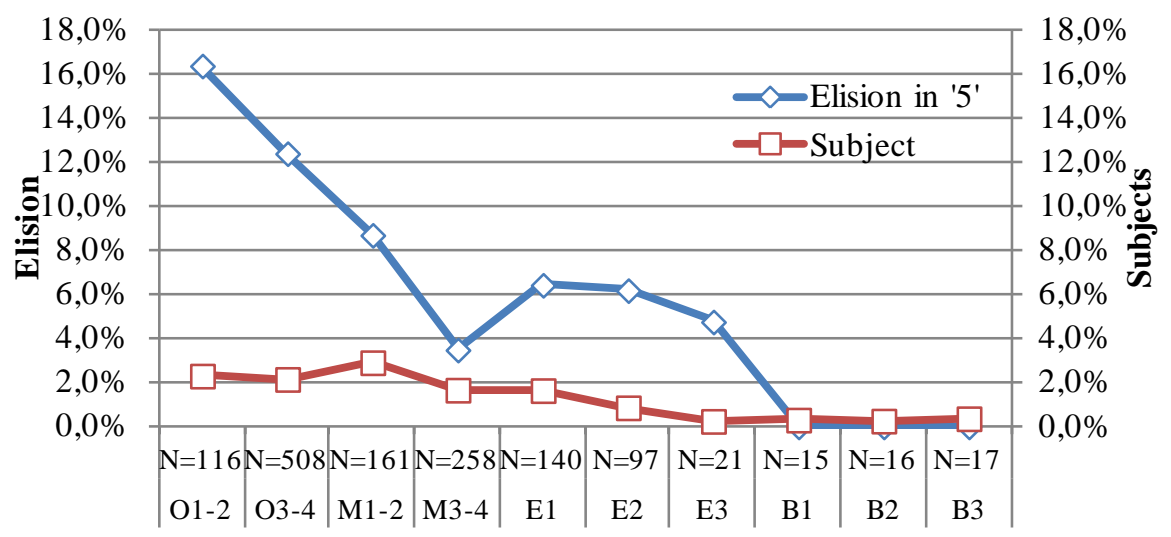

Figure 6 Relative subject elision at position "5"

The behaviour at position "5" largely confirms the hypothesis this paper started out with: the decline in the number of subjects showing subject properties is at least faster than the loss of the subject position (at least until eModE, after which the numbers become too low). However, none of the transitions (including the seemingly large drop from E3 to B1) is significant enough, since the number of observed elisions in position " 5 " simply is too low. The results for position "5", then, cannot be taken into account for the overall evaluation that is needed to answer the research question.

(10) a. ac me wæs onsigendese stranga wynd

$$
\begin{aligned}
& \text { but to.me was descending the strong wind } \\
& \text { and _me gebrohthæfđonpas stowe, [covinsal:30-31] } \\
& \text { and _ me brought has on this place }
\end{aligned}
$$

pæt ic nat hwaric eom.

that I know.not where I am

"But there was a strong wind descending onto me, which took me to this place, so that I don't know where I am."

\footnotetext{
${ }^{18}$ None of the transitions in the "Elision" line are significant according to the two-tailed Fisher's $(\mathrm{p}<0,01)$. The macro-level transitions (OE $>$ ME $>$ eModE $>$ LmodE) are not significant either.
} 
b. The ix day of Desember dyd pryche at Powlles crosse doctur Borne, bysshope of Bathe,

and _ prayd for the pope of Rome Julius the thurde, and for alle the solles of purgatory. [machyn-e1-p2:304-305]

The clause-final subject 'the strong wind' in the OE example in (10a) is elided in the next clause, something which is impossible in PDE. One of the last times it is encountered is in the EmodE example in (10b), where the subject "doctur Borne" is clause-final in its clause, and then ellipted in the following clause.

\subsubsection{The Fore Field position "1"}

The two subject positions in the Fore Field too undergo changes, as can be learned from Figure 2: the clause-initial position "1" is overtaken by position "2", which is the one immediately preceding the finite verb, while another constituent precedes the subject. Figure 7 shows the behaviour of position " 1 ". 19

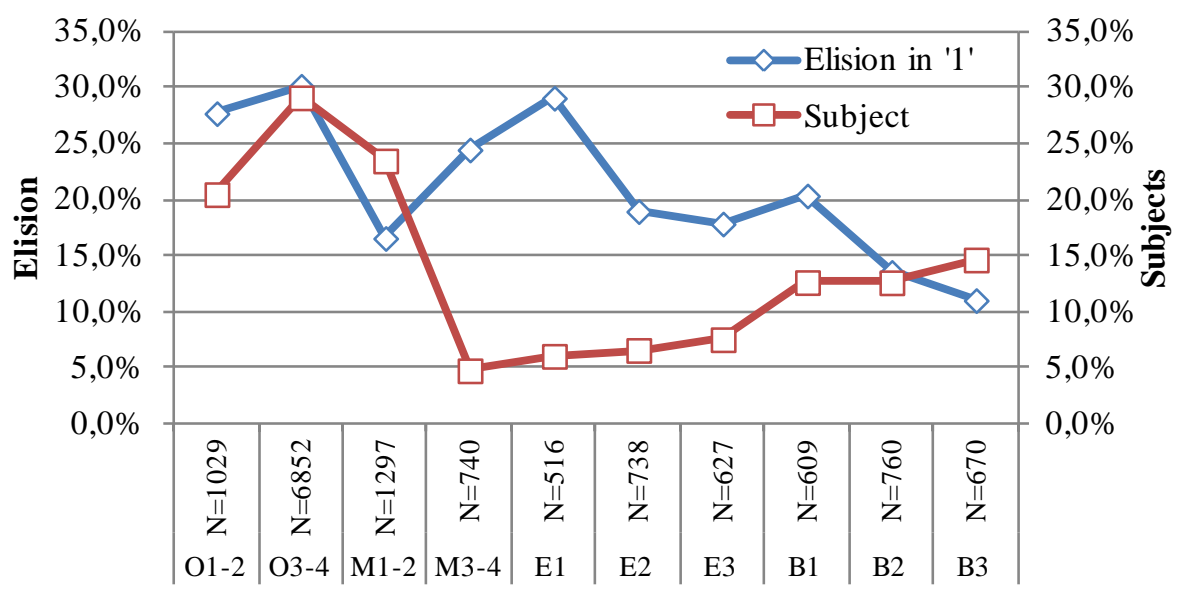

Figure 7 Relative subject elision at position " 1 ”

The kinds of clauses categorized as having a position " 1 " subject seem to be a bit of a mixed bag, as illustrated by (11a), a temporal adverb $p a$ 'then' insertion, and $(11 b, c)$, which have participial phrase insertions after the subject. However, while the temporal adverb $b a$ 'then' has disappeared from the second position,

\footnotetext{
${ }^{19}$ The following transitions in the "Elision" line are significant according to the two-tailed Fisher's exact test $(\mathrm{p}<0,01)$ : O3-4 > M1-2, M1-2 > M3-4, E1 > E2, B1 > B2. On a higher level, the transitions $\mathrm{OE}>\mathrm{ME}$ and $\mathrm{eModE}>\operatorname{LmodE}$ are significant $(\mathrm{p}<0,01)$.
} 
both the $\mathrm{OE}$ then-insertion and the later participial phrase insertion are instances of 'fillers': elements that, among others, can serve to signal topic-switch (Levinsohn, 2009). The clause-initial Fore Field position "1" rapidly declines from OE, as illustrated in (11a), to ME, as in (11b), but afterwards, it gradually regains some of its significance (from the larger picture in Figure 2 we know that this is, in fact, 'relative significance' that can largely be attributed to the continuous decline of positions " $3-5$ "). The proportion of subjects displaying the elision property fluctuates, but there seems to be a declining trend overall. Subject elision is still possible at the end of LmodE, witness (11c).

$$
\begin{aligned}
& \text { a. He ba for hi gebæd, [coeuphr:100-101] } \\
& \text { she then for him prayed } \\
& \text { and _hi gebletsode } \\
& \text { and _him blessed } \\
& \text { "She prayed for him and blessed him." }
\end{aligned}
$$

b. Pis goodLadie, heryng pis message, [cmroyal:361-362]

$$
\begin{aligned}
& \text { this good lady hearing this message } \\
& \text { assentid vn-to pe will of God, } \\
& \text { agreed to the will of God } \\
& \text { and _ in pe mostlowly wize answerd. } \\
& \text { and _ in the most humble way replied }
\end{aligned}
$$

"This good lady, upon hearing this message, agreed to God's will, and replied in the most humble way."

c. The enemy, perceiving this, descended from the mountains

and _ laid siege to the ship, which was fast upon the dry sands.

[bradley-1905:170-171]

Not all of the fluctuations visible in Figure 7 are, in fact, significant (see footnote 19). Be that as it may, position " 1 " shows behaviour that does not really confirm the hypothesis stated in the introduction: the crucial transition from M1-2 to M34 shows an increase in the proportion of subjects displaying subject properties in position " 1 ", whereas there is a decrease in the proportion of subjects occurring in that position. It is only in eModE (E1) and LmodE (B1) that the decrease in the percentage of subjects displaying subject properties sets in. 


\subsubsection{The Fore Field position "2"}

The second position in the Fore Field is the one immediately preceding the finite verb, provided a different constituent precedes the subject. ${ }^{20}$

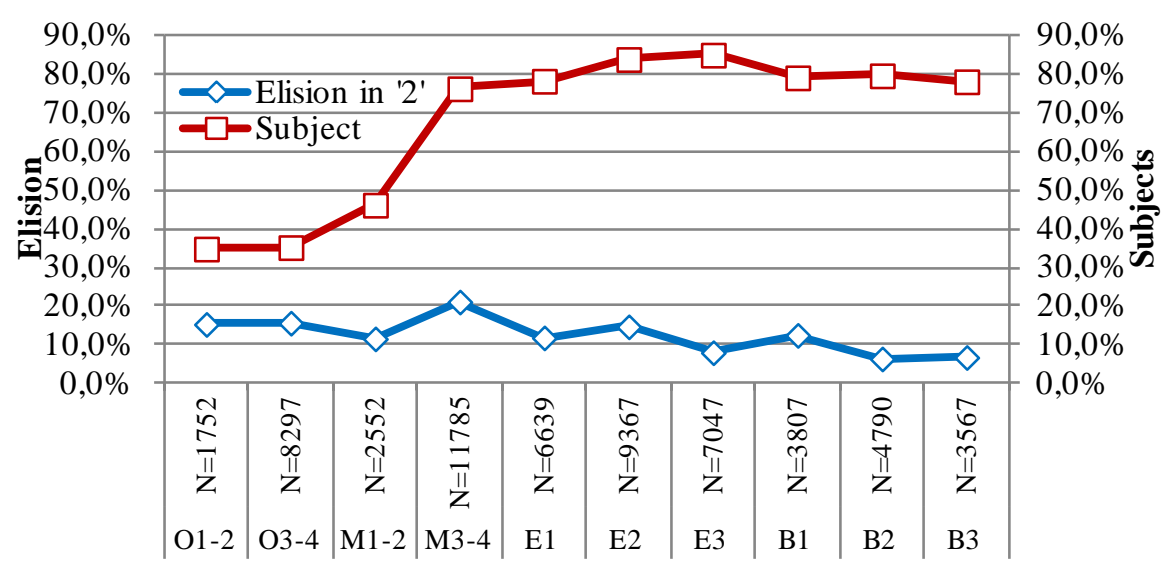

Figure 8 Relative subject elision at position “2”

The picture displayed by position "2" differs from the one displayed by position " 1 ": the slight decrease in subject properties associated with this position (starting in eModE) precedes the decrease in the subject position as a whole (starting only in LmodE).

a. Đa Angel peod\& Seaxnawæs gelađod

then English people \& Saxon were invited

fram bam foresprecenan cyninge

by the aforementioned king

\& _onBreotone com onbrim myclum scypum;

and _ to Britain came on three large ships

"Then, the English and West Saxon people were invited by the king that has been mentioned earlier, and they came to Britain on three large ships."

\footnotetext{
${ }^{20}$ The following transitions are significant according to the two-tailed Fisher's exact test $(\mathrm{p}<0,01)$ : O3-4 > M1-2, M3-4 > E1, E1 > E2, E2 > E3, E3 > B1, B1 > B2. On a higher level, the transitions $\mathrm{OE}>\mathrm{ME}>\mathrm{eModE}>\mathrm{LmodE}$ are all significant, which means that there is an overall downward trend.
} 
b. One day another species of biscuit was substituted,

and _ was received with disfavour

and rejected.

[benson-1908:442-443]

Subject elision under coordination takes place in OE, as exemplified in (12a), as well as in LmodE, as in (12b).

\subsection{Subject-verb relations}

As suggested in (7e), one subject 'property' of a particular subject position can be expressed as the kinds of lexical verbs that subjects occurring in a particular position associate with. The queries that look for this property discern five subject-verb relations:

\section{(13) Subject-verb associations}

"S" Subject of an intransitive verb

"B” Subject of a copula clause

“A” Subject of a transitive verb

"P” Subject of a verb in the passive voice

"Other" The kind of subject cannot be determined automatically

If there would be no preference for types of subjects to occur in particular positions, all five subject positions (position " 1 " and " 2 " in the Fore Field, " 3 " in the Middle Field, and " 4 " and " 5 " in the Post Field) would have a similar distribution of subject types $\mathrm{S} / \mathrm{B} / \mathrm{A} / \mathrm{P}$, and this distribution would not change over time. But this is not what the queries on the historical English data reveal.

\subsubsection{Subject type distribution in the Fore Field}

There are two subject positions that I, according to (3), discern in the Fore Field: the clause-initial position " 1 ", and the immediately preverbal position " 2 ". Their behaviour is not completely the same, as can be learned from Figure 9. 

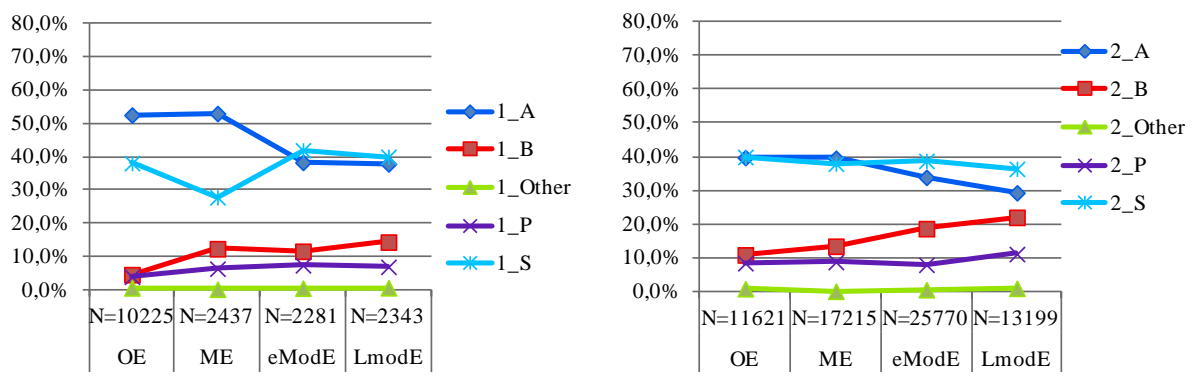

Figure 9 Subject type distribution in positions "1" and "2"

The clause-initial position " 1 " in OE starts out with a mixture of transitive verb subjects "A", as for instance (14a), and intransitive verb subjects " $S$ ", while copula clause subjects "B" are minimal. The immediately preverbal position "2" looks similar, except that it has a larger percentage of copula clause subjects " $\mathrm{B}$ ", such as (14b).

(14) a. Secyningc pahim andswarode bysmerigende, ... the king then him answered mocking [cochristoph:31]

"The king answered him mockingly."

b. Witodlice se geleafe byđ unnytt

[coalcuin:16]

truly the faith is no.use
buten pan gode weorcan,
without the good works
"Faith is really of no use if it is not accompanied by good deeds."

The distribution of subject types for these positions changes gradually over time, so that by LmodE the immediately preverbal position "2" hosts a very diverse amount of subject types. The clause-initial position " 1 " strongly favours the " $A$ " and "S" subject types, each almost $40 \%$, but there is some room for " $\mathrm{B}$ " and "P" subject types, each taking roughly $10 \%$.

To sum up, position " 1 " has changed quantitatively, but remains its character as hosting preferably " $\mathrm{A}$ " and " $\mathrm{S}$ " subjects, but position " 2 " has changed from a preferentially "A"/"S" subject type host to a true multi-purpose one. This is exactly what we would have expected intuitively: the immediately preverbal subject position is the most general one in PDE, and, consequently, the most versatile one. 


\subsubsection{Subject type distribution in the Middle Field}

The Middle Field position " 3 " starts out in OE with a preference for one kind of subject, but ends in LmodE with a more diverse nature, as can be seen in Figure 10.

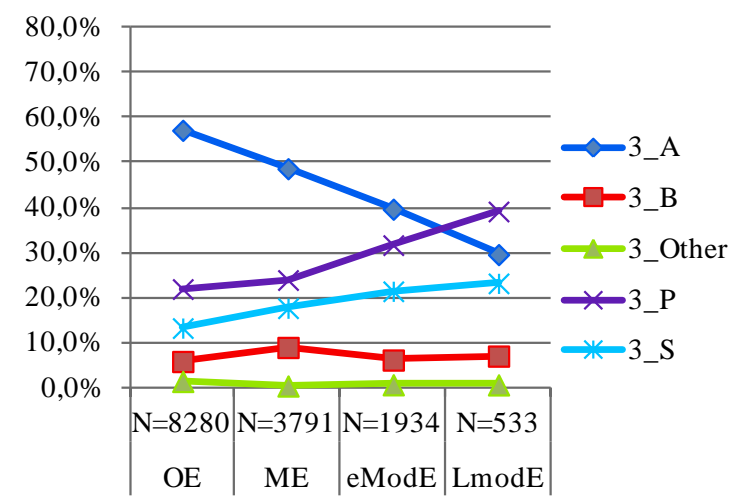

Figure 10 Subject type distribution in Middle Field position "3"

The subjects occurring in position " 3 " primarily belong to two groups: subjects of verbs in the active voice "A", such as (15a), and subjects of verbs in the passive voice "P", such as (15b). The preference was for "A" subjects in OE, and shifts to "P" subjects in LmodE.

(15) a. First sal tu seke godis rengne and his rihtuisne [cmbenrul:204] first shall you seek God's rule and his righteousness

'You should first look for God's kingdom and His righteousness.'

b. Sua salle hir fautes be mendid [cmbenrul:734]

thus shall her mistakes be repaired

"This is how her mistakes should be amended."

The decline of the Middle Field subject position " 3 ", then, as illustrated in Figure 2 , appears to correlate with its decreasing ability to host "A" subjects.

\subsubsection{Subject type distribution in the Post Field}

The Post Field hosts two subject positions, the immediately postverbal one " 4 " and the clause-final one " 5 ". Figure 2 has shown that position " 4 " only plays a marginal role at any point in history, and that position " 5 " gradually decreases over time. The subject type distribution of these two positions is shown in Figure 11. 

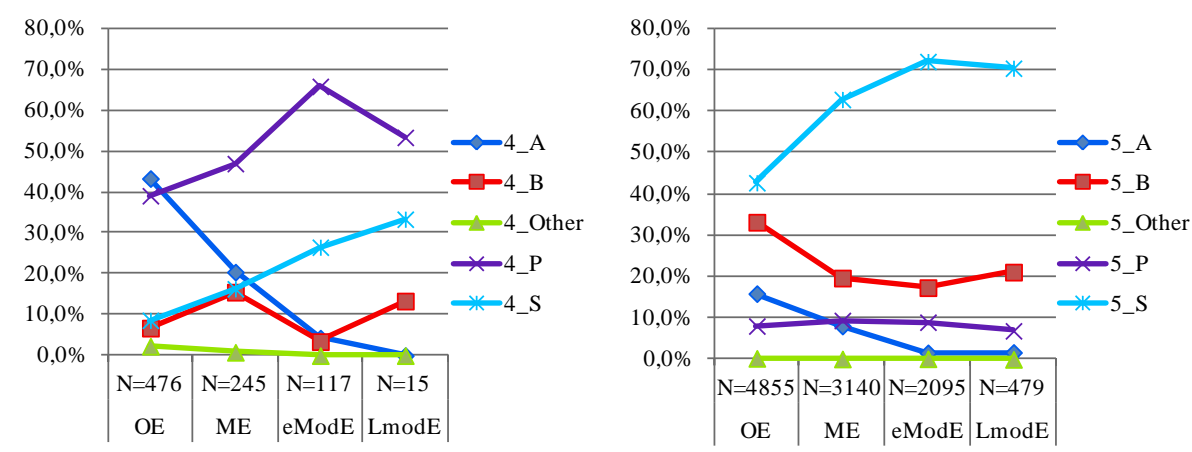

Figure 11 Subject type distribution in Post Field positions "4" and "5"

The picture for the immediately postverbal position " 4 " reveals a clear prevalence throughout for hosting subjects of passives "P”, as in (16a) for OE. Transitive verb subjects "A" make up 20\% in OE, as in (16b), but they disappear by eModE. The rise of intransitive subject types "S", combined with the "P" prevalence, earmarks this position increasingly as a presentational one. ${ }^{21}$ The "B" subjects hold their ground in a limited way, even into LmodE, as in (16c). The intransitive " $\mathrm{S}$ " subjects steadily increase to over 30\% in LmodE, as in (16d).

(16) a. and weard eft gefylled pæt twelffealde getel[coaelhom:1042]

and was again fulfilled that twelfth number

onpam twelfapostolum

on the twelve apostles

"Then the twelveforld number of the apostles was again completed."

b. \& pis wæs cwepende se eadiga Petrus [coblick:1788]

\& this was saying the blessed Peter

to eallum pæmapostolum

to all the apostles.

"And Peter was saying this to all of the apostles."

\footnotetext{
${ }^{21}$ There is a general tendency for 'new' information to occur late in a sentence, the 'Principle of natural information flow' (1964). Since both ' $S$ ' and 'P' subjects occur in sentences that concentrate on one participant, it seems quite likely that they are used for the introduction of new participants.
} 
c. Such might be the system of the Gnome at the very same time that the followers of Leibnitz, ..., would be teaching the doctrine of gradual refrigeration.

[lyell-1830:117]

d. and so rolls on this ball of destruction till the whole country is on the alert.

[reade-1863:423]

Position "5", also in the Post Field, undergoes a change over time too. While it continues to host "P" subjects from OE (17a) to LmodE (17b), its weak preference for intransitive " $\mathrm{S}$ " subjects in $\mathrm{OE}$ increases to a strong preference in LmodE, as in (17c). ${ }^{22}$

(17)
a. Her is ahangen
se Nazarenisca hælend
[coverhome:286]
here is hung the Nazarene
saviour
se is Iudea cyning.
who is Judea's king

'The Saviour from Nazareth, who is king of Judea, has been hung here.'

b. At the top is a circular disk,

and to this is attached a cylindrical segment. [ [strutt-1890:234]

c. After English, should come German and French. [bain-1878:427]

\subsubsection{Subject type specificity}

I have shown how the distribution of the subject types varies over time for the five subject positions, and this variation correlates in two different ways with the loss of a subject position: (a) the decline in position " 3 " subjects coincides with a decreasing preference for one particular subject type, but (b) the decline in position " 5 " subjects goes hand in hand with an increasing preference for one particular subject type (the intransitive "S" subjects). This section links the "preference" for particular subject types to a measure: the specificity.

As stated in section 4, I argue that an increasing specificity of a subject position in terms of subject type distribution correlates with this position's

\footnotetext{
22 The number of subjects that unequivocally appear in position “ 5 ” has, however, decreased radically (OE: 101, LmodE: 14), so that measuring the subject type distribution is tentative.
} 
entrenchment, and, ultimately, its loss. As a measure of specificity of a subject position, I propose to take the normalized standard deviation as a basis: ${ }^{23}$

$$
\text { SubjectTypeSpecificity }=10 * \frac{\text { Standard Deviation }_{(\text {Subject types })}}{\text { number of subjects }}
$$

The standard deviation between the values of the subject types "A", "B", "P" and " $S$ " in one position shows how much variation there is in the percentage of subject types; the standard deviation will be zero, when all subject types are present in an equal amount. ${ }^{24}$ The "specificity" of a subject position is then minimal. With an increasing standard deviation, the specificity necessarily increases, since a high standard deviation means that one or two particular subject types are relatively more present.

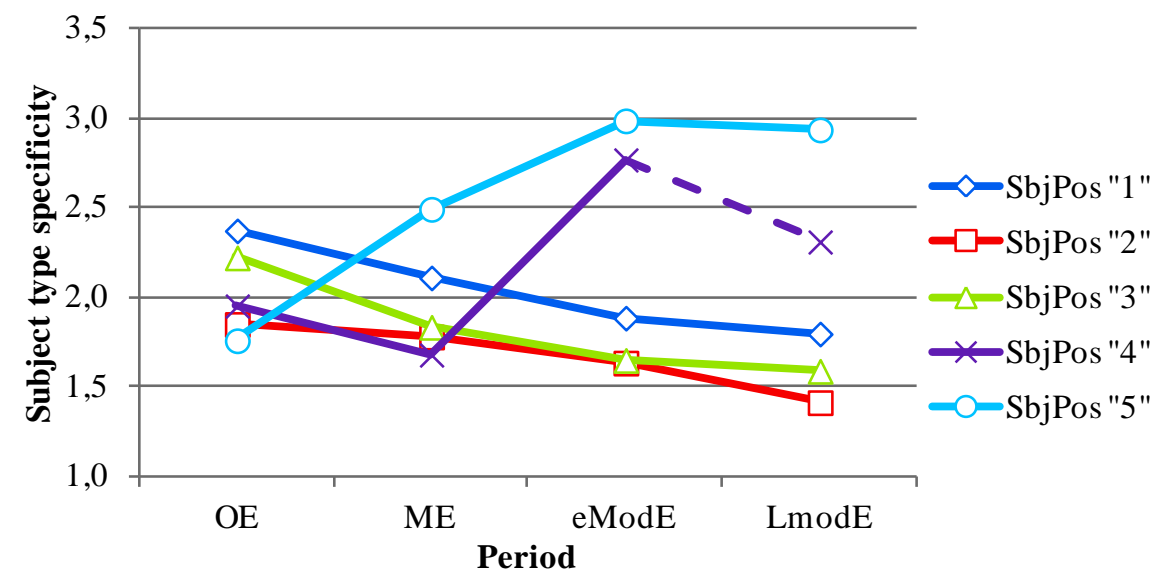

Figure 12 Subject type specificity per subject position

\footnotetext{
${ }^{23}$ The number ' 10 ' is, perhaps, a bit arbitrariy; it is chosen so that the specificity numbers are above 1 sooner than the normalized standard deviation would. The standard deviation is arrived as follows: (a) calculate the mean of a group of numbers, (b) sum up the squares of the differences between each number and the mean, (c) divide this sum by the amount of numbers, (d) take the square root of the result. The 'normalized' standard deviation divides this number by the sum total of the group of numbers.

${ }^{24}$ Subjects in position 1 in OE, for instance, are divided over the different types as: $\mathrm{A}=5371$, $\mathrm{B}=476, \mathrm{P}=411, \mathrm{~S}=3896$, Other=71. The standard deviation between these numbers is 2424,7. Normalization to 0,237 is arrived by division through 10225 (the sum of all subjects: $5371+476+411+3896+71)$. Multiplying this normalized standard deviation with 10 yields a specificity of 2,4 .
} 
What Figure 12 shows is that the Fore Field positions " 1 " and "2" become less specific over time; they become more versatile, and this versatility may be linked to their prominence. The Middle Field position "3" also decreases in specificity, and this too seems to be linked to its continuing existence: even though it is numerically not too high, it has found a purpose for a wide variety of subject types.

The immediately postverbal position " 4 " sees an increase in specificity in eModE, which correlates with its attrition (the decline in LmodE is not significant due to low numbers - see Figure 11). The clause-final position " 5 " reaches the highest overall level of specificity. It is not clear, however, that this should be correlated to an imminent complete departure of the position; while its role of hosting intransitive " $\mathrm{S}$ " subjects is adequately taken care of by other positions too, its function in terms of presentational focus appears to keep its existence legitimate.

\section{Conclusions and discussion}

The aim of this paper has been to test the hypothesis that attrition of a subject position is preceded by a decline in subject properties associated with a particular position. In order to verify this hypothesis, I have queried the main-clause subjects in the historical English corpora, in order to retrieve the number of subjects displaying (a) subject elision under coordination, and I have also measured (b) the subject type specificity associated with each subject position over time. The results from these two experiments start unfolding an interesting picture.

The test for subject elision under conjunction reveals that the numerical decline in the Middle Field position (" 3 ") is preceded by a more rapid decline in the proportion of subjects displaying this property, and the same holds for clause-final subjects (position " 5 ”). Neither position has disappeared completely, though.

The subject type specificity discerns four basic types: subjects of copula clauses, subjects of intransitive clauses, subjects of active voice transitive clauses and subjects of passive voice transitive clauses. One hypothesis here would be that a rise in specificity for a particular position is a forewarning of this position's disappearance. This claim is partly borne out by the data. Position " 1 " and "2" show an overall decrease in specificity; they become the most diverse positions in LmodE, which fits their character as 'conquering' subject positions. The Middle Field position "3" sees a similar decrease in specificity, which marks it as a stable position, since the position is no longer restrict to one particular subject type. This should not come as a surprise, given the fact that it is one of the main subject positions that is used in the syntacticized verb-second remnant of English. The Post Field position " 4 " has increased in specificity by 
eModE, and so has the specificity of position " 5 ". Subjects in these positions have become entrenched for particular purposes. Yet, unless another construction is going to be used for the presentational purposes served by " 5 ”, it is unlikely to disappear any time soon.

Future research should attempt to define more automatically determinable subject properties. A related, but slightly different matter of research is the investigation of how a number of not-subject-specific NP properties differ and change over time: subject length (are longer/shorter subjects occurring in particular positions?) and the distribution of NP-types (such as demonstratives, proper nouns etc). Van Kemenade's work has already indicated that there is a Pronoun-LexicalNP opposition that plays a role in the positions "2" versus " 3 " in OE, and it would be interesting to see how a finer-graded NP-type distribution changes per subject position over time. Follow-up research could also zoom in more on the verb-type distribution, making finer distinctions than have been made now, such as subdividing the intransitive subjects into unaccusatives and unergatives, as is done in research by van Kemenade and Westergaard (2012).

\section{Acknowledgements}

The author would like to thank Olaf Koeneman, Meta Links, Bettelou Los, Gea Dreschler and an anonymous reviewer for helpful comments and suggestions.

\section{References}

Allen, Cynthia L. 1995. Case marking and reanalysis : grammatical relations from Old to early modern English. Oxford; New York: Clarendon Press ; Oxford University Press.

Behaghel, Otto. 1909. "Beziehungen zwischen Umfang und Reihenfolge von Satzgliedern”. Indogermanische Forschungen 25:110-142.

Biberauer, Theresa, and Ans van Kemenade. 2011. "Subject Positions and Information-Structural Diversification in the History of English". Catalan Journal of Linguistics 10:17-69.

Boag, Scott, Don Chamberlin, Mary F. Fernández, Daniela Florescu, Jonathan Robie, and Jérôme Siméon. 2010. XQuery 1.0: An XML Query Language (Second Edition): W3C Recommendation, <http://www.w3.org/XML/Query/\#specs >.

Burzio, Luigi. 1986. Italian syntax : a government-binding approach. Dordrecht; Boston; Hingham, MA: Reidel.

Cole, Peter, Wayne Harbert, Gabriella Hermon, and S. N. Sridhar. 1980. "The Acquisition of Subjecthood". Language 56:719-743.

Coniglio, Marco. 2013. On German modal particles and their interaction with illocutionary force and clause type. In The role of modal particles in speech acts. Venice, Italy: (unpublished). 
Firbas, Jan. 1964. 'From comparative word-order studies (thoughts on L.V. Mathesius' conception of the word-order system in English compared with that in Czech)". BRNO studies in English 4:111-126.

Hinterhölzl, Ronald, and Ans van Kemenade. 2012. "The interaction between syntax, information structure and prosody in word order change”. The Oxford Handbook of the History of English. ed. by Elizabeth Closs Traugott and Terttu Nevalainen, 803821. New York, Oxford University Press.

Hulk, Aafke, and Ans van Kemenade. 1993. “Subjects, nominative case, agreement and functional heads”. Lingua 89:181-215.

Keenan, E. L. 1975. “Towards a universal definition of "subject"”. Subject and Topic. ed. by Charles N. Li, 303-333. University of California, Academic Press.

van Kemenade, Ans. 1987. Syntactic case and morphological case in the history of English. Dordrecht: Foris publications.

van Kemenade, Ans. 1999. “Sentential negation and word order in Old English”. Negation in the history of English. ed. by Ingrid Tieken-Boon van Ostade, Gunnel Tottie and Wim van der Wurff 147-166. Berlin, Mouton de Gruyter.

van Kemenade, Ans, and Marit Westergaard. 2012. "Syntax and Information Structure: verb second variation in Middle English”. Information Structure and Syntactic Change in the History of English. 1, ed. by Bettelou Los, María José López-Couso and Anneli Meurman-Solin, 87-118. New York, Oxford University Press.

Komen, Erwin R. 2013. Finding focus: a study of the historical development of focus in English. Utrecht: LOT.

Kroch, Anthony, Beatrice Santorini, and Ariel Diertani. 2004. Penn-Helsinki Parsed Corpus of Early Modern English, < $\underline{\text { http://www.ling.upenn.edu/hist- }}$ corpora/PPCEME-RELEASE-2/index.html $>$.

Kroch, Anthony, Beatrice Santorini, and Ariel Diertani. 2010. Penn parsed corpus of modern British English, < http://www.ling.upenn.edu/hist-corpora/PPCMBE-

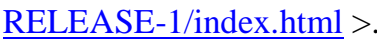

Kroch, Anthony, and Ann Taylor. 2000. Penn-Helsinki Parsed Corpus of Middle English, second edition., <http://www.ling.upenn.edu/hist-corpora/PPCME2RELEASE-2/ > .

Lambrecht, Knud. 2010. "Constraints on the subject-focus mapping in French and English”. Comparative and contrastive studies of information structure. ed. by Carsten Breul and Edward Göbbel, 77-99. Amsterdam/Philadelphia, John Benjamins.

Levinsohn, Stephen. 2009. Self-instruction materials on narrative discourse analysis: SIL-International, < www.sil.org/ levinsohns/narr.pdf $>$.

Los, Bettelou, and Gea Dreschler. 2012. "The loss of local anchoring: From adverbial local anchors to permissive subjects”. Rethinking Approaches to the History of 
English. ed. by Terttu Nevalainen and Elizabeth Closs Traugott, 859-872. New York, Oxford University Press.

Los, Bettelou, María José López-Couso, and Anneli Meurman-Solin. 2012. “On the interplay of syntax and information structure". Information structure and syntactic change in the history of English. ed. by Anneli Meurman-Solin, María José LópezCouso and Bettelou Los, 3-18. New York, Oxford University Press.

Prince, Ellen. 1992. "The ZPG letter: subjects, definiteness and information-status”. Discourse description: diverse analyses of a fund raising text. ed. by S. Thompson and W. Mann, 295-325. Philadelphia/Amsterdam, John Benjamins B.V.

Rissanen, Matti. 1999. "Isn't it? or is it not? On the order of postverbal subject and negative particle in the history of English”. Negation in the history of English. ed. by Ingrid Tieken-Boon van Ostade, Gunnel Tottie and Wim van der Wurff, 189204. Berlin, Mouton de Gruyter.

Speyer, Augustin. 2010. "German Vorfeld-filling as constraint interaction”. Constraints in discourse. ed. by Anton Benz and Peter Kühnlein, 267-290. Berlin/New York, John Benjamins.

Taylor, Ann, Athony Warner, Susan Pintzuk, and Frank Beths. 2003. The YorkToronto-Helsinki Parsed Corpus of Old English Prose, <http://wwwusers.york.ac.uk/ lang22/YCOE/YcoeHome.htm >.

Warner, Anthony. 2007. "Parameters of variation between verb-subject and subjectverb order in late Middle English”. English Language and Linguistics 11:81-111. 